\title{
"Efemeridades e Persistências": exposição e ações educativas em uma escola de educação formal
}

"Ephemeralities and Persistences": an exhibition and educational actions in a formal education school

Juliana Rossi Gonçalves ${ }^{1}$ Taiza Mara Rauen Moraes ${ }^{2}$

\footnotetext{
1 Doutoranda em Patrimônio Cultural e Sociedade pela Universidade da Região de Joinville (UNIVILLE) e Mestre em Educação pela UNIVILLE. É especialista em ArteEducação pela Faculdade Pe. João Bagozzi (Curitiba/PR) e licenciada em Artes Visuais (UNIVILLE). Atua como professora de Desenho e Pintura na Escola de Artes Fritz Alt em Joinville/SC.

Lattes: http://lattes.cnpq.br/1133178456717309

E-mail: julirossi@gmail.com

2 Doutora e Mestre em Literatura pela Universidade Federal de Santa Catarina (UFSC). Possui graduação em Letras pela Universidade do Contestado (UnC). É professora titular da Universidade da Região de Joinville (UNIVILLE) no Programa de Pós-Graduação em Patrimônio Cultural e Sociedade e no curso de Licenciatura em Letras.

Lattes: http://lattes.cnpq.br/5574002164226642

E-mail: moraes.taiza@gmail.com
} 


\title{
Resumo
}

O artigo aborda as proposições e ações educativas realizadas na exposição "Efemeridades e Persistências", cujo tema foi lançado na disciplina "Ação Educativa em Espaços Culturais", do Programa de Pós-Graduação em Artes Visuais (PPGAV) da Universidade do Estado de Santa Catarina (UDESC). Projeto de arte contemporânea realizado no "Espaço Estético" do Colégio de Aplicação da Universidade Federal de Santa Catarina (UFSC) em Florianópolis/SC, no ano de 2018, integrou discentes que são professoras/educadoras de núcleos pedagógicos de universidades, institutos, escolas e instituições culturais. Bem como, desvelou desafios em decorrência de dois fatores: desenvolvimento de uma proposta expositiva em espaço escolar de educação formal articulado a uma mediação cultural para um público específico.

\section{Palavras-chave}

exposição; ação educativa; efemeridades; persistências.

\begin{abstract}
The article approaches the educational proposals and activities carried out in the exhibition "Ephemerality and Persistence", whose theme was launched in the discipline "Educational Action in Cultural Institutions", from the Postgraduate Program in Visual Arts (PPGAV) of the University of the State of Santa Catarina (UDESC). The contemporary art project carried out the "Aesthetic Space" of the Colégio de Aplicação of the Federal University of Santa Catarina (UFSC) in Florianópolis/SC, Brazil, in 2018, which integrated alumni who are teachers/ educators from universities, institutes, schools and cultural institutions. It revealed challenges due to two factors: development of an exhibition proposal in a formal education school, linked to a cultural mediation for a specific audience.
\end{abstract}

\section{Keywords}

exhibition; educational action; ephemerality; persistence.

ISSN: 2447-1267 


\section{Introdução: a disciplina "Ação Educativa em Espaços Culturais"}

Esse artigo aborda a concepção, produção e ações educativas da exposição intitulada "Efemeridades e Persistências", realizada em junho de 2018 pelas mestrandas e doutorandas da disciplina "Ação Educativa em Espaços Culturais", vinculada ao Programa de Pós-Graduação em Artes Visuais (PPGAV) da Universidade do Estado de Santa Catarina (UDESC) e ministrada pela Professora Doutora Sandra Regina Ramalho e Oliveira.

A proposta de desenvolvimento da disciplina foi projetada em duas etapas. A etapa inicial ocorreu no primeiro semestre de 2018 com a abordagem de diversas concepções de museus, espaços expositivos contemporâneos, mediação cultural e relação do público com os museus, tendo como embasamento teórico livros, artigos, websites de instituições culturais e materiais educativos produzidos para exposições. Os autores fundantes acionados foram Martin Grossmann (2011), Pablo Helguera (2011), Rejane Coutinho (2013), Miriam Celeste Martins (2014), Luciana Chen (2014). Enquanto a segunda etapa foi centrada no desenvolvimento do projeto.

A disciplina teve como locus museus e instituições culturais de Florianópolis/ SC, objetivando vivências educativas em espaços culturais. Em cada espaço visitado, os educadores das instituições fizeram visitas mediadas com a turma da disciplina, produzindo imersões culturais.

A segunda etapa da disciplina consistiu em pensar, materializar e mediar uma exposição de arte contemporânea tematizando "Efemeridades e Persistências".

O artigo relata o desenvolvimento de ações educativas acopladas a uma exposição de arte contemporânea no contexto escolar e as questões desencadeadoras do processo de concepção da exposição tematizada sob o viés do patrimônio histórico e cultural.

\section{Efemeridades e Persistências: da concepção à criação}

O projeto expositivo dirigido para um espaço escolar se constituiu num desafio para as alunas propositoras ${ }^{1}$ da exposição "Efemeridades e Persistências". No processo foram enfrentados questões e conflitos como: desenvolvimento/criação de um trabalho artístico a partir de tema pré-definido e de uma produção artística individual dirigida a um público-alvo específico, os alunos do Colégio de Aplicação da Universidade Federal de Santa Catarina (CA-UFSC).

As etapas seguidas para o desenvolvimento do projeto foram: concepção, criação artística e ações educativas. Atreladas ao conceito de "efemeridade', que conforme Ramalho e Oliveira (2018) demanda a percepção da fluidez,

1 Nesse artigo as discentes da disciplina serão chamadas de "alunas propositoras" para propor uma melhor leitura do texto como uma tentativa de englobar os termos: aluna/professora/artista/mediadora. 
Ao se tomar o termo efemeridade - e seus respectivos efeitos de sentidos, como conceito curatorial, difícil é escapar da tentação de enveredar por dois focos, distintos: a efemeridade da vida e a efemeridade da arte.

O conceito de "efemeridade" remete ao que dura pouco e ao que é passageiro. A efemeridade da vida relaciona-se a sua finitude: toda vida, seja humana, vegetal ou animal, tem um fim. Já a efemeridade da arte é uma das marcas dos trabalhos contemporâneos, como na land art, performance, grafitti ou pintura mural, propostas estéticas que colocam em xeque a perenidade da arte. A fotografia foi utilizada para o registro das imagens constituintes do projeto expositivo, a partir do conceito de que a imagem fotografada capta a efemeridade da ação ou do momento que existiu em um determinado dia, horário e local para registrá-lo/fixá-lo.

A ideia de efemeridade e seu oposto, a persistência, que é aquilo que dura, que permanece, foi acionada como desencadeadora do processo. Entendemos que a persistência na arte está presente em galerias, museus, cavernas, por meio de obras que atravessam anos e até séculos de existência. Algumas obras persistem, mas as exposições de arte são efêmeras, pois mudam conforme o espaço e proporcionam experiências exclusivas de determinado momento de interação, curadoria e montagem (RAMALHO e OLIVEIRA, 2018).

Na vida, a permanência está na existência das coisas produzidas pelos humanos, como estradas, construções, edifícios, casas e coisas-objetos que permanecem em casas e museus. Há também persistências não materiais que podem ser passadas de geração em geração, como conhecimentos, sabedorias, descobertas (RAMALHO E OLIVEIRA, 2018). Na natureza, ela existe na cadência das estações, na resistência e renovação dos biomas. Esses temas podem ter inúmeros desdobramentos, a partir de diversas áreas de estudos, conceitos e pontos de vista.

Cada aluna propositora trabalhou com um subtema sob o viés da efemeridade e persistência, como: ciclos da moda, bolhas da espuma da água do mar, inclusão de pessoas com deficiência intelectual, filhos, pensamentos no papel, patrimônio histórico e cultural.

No tocante à abordagem do patrimônio histórico e cultural foram selecionados locais turísticos da cidade de Joinville/SC. A decisão pela escolha dessa cidade deveu-se ao fato de que a discente propositora do trabalho em questão é moradora dessa cidade.

A proposta foi desencadeada pela seleção de bens patrimoniais materiais tombados, da cidade de Joinville/SC, que atualmente são espaços culturais e que representam um valor histórico, artístico e cultural. $\bigcirc$ objetivo da seleção foi discutir os movimentos das políticas de gestão patrimonial, que em determinados períodos valorizam alguns bens e em outros os tornam "invisíveis", devido à falta de manutenção desses espaços ou fechamento/reforma por um longo período (GONÇALVES, 2018).

O trabalho é composto por três fotografias coloridas manipuladas digitalmente (fig. 1) de tamanho $A 3(42 \times 30 \mathrm{~cm})$, formando assim um tríptico. O título do trabalho, "Patrimônio em branco", remete ao vazio deixado nas fotografias pela extração digital de cada patrimônio fotografado. 


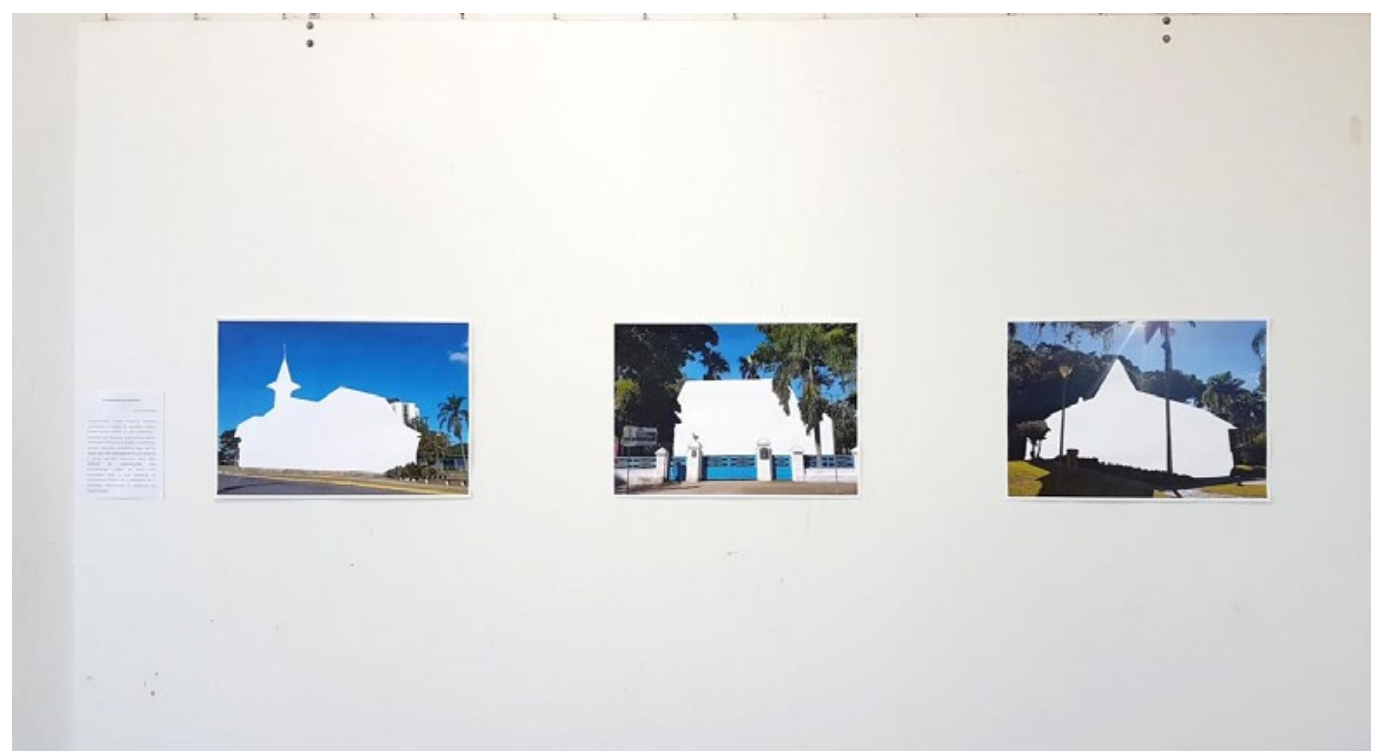

Fig. 1. Juliana Rossi Gonçalves. "Patrimônio em branco", 2018. Três fotografias coloridas em papel couché, 42 × $30 \mathrm{~cm}$ cada. Tríptico exposto na mostra "Efemeridades e Persistências" do Espaço Estético do Colégio de Aplicação da UFSC, em Florianópolis/SC, de 12 a 29 de junho de 2018.

Em cada foto o processo de manipulação da imagem utilizado foi a retirada/ apagamento digital da fachada da construção arquitetônica do patrimônio tombado, objetivando o apagamento de detalhes identificadores dos locais patrimonializados (figs. 2, 3 e 4).

As fotografias manipuladas marcam pela ausência dos bens construídos e em contraponto tornam visíveis a paisagem e o entorno da construção. Ressalta-se que os bens patrimoniais foram selecionados para as fotografias devido às suas localizações em pontos estratégicos da cidade de Joinville/SC.

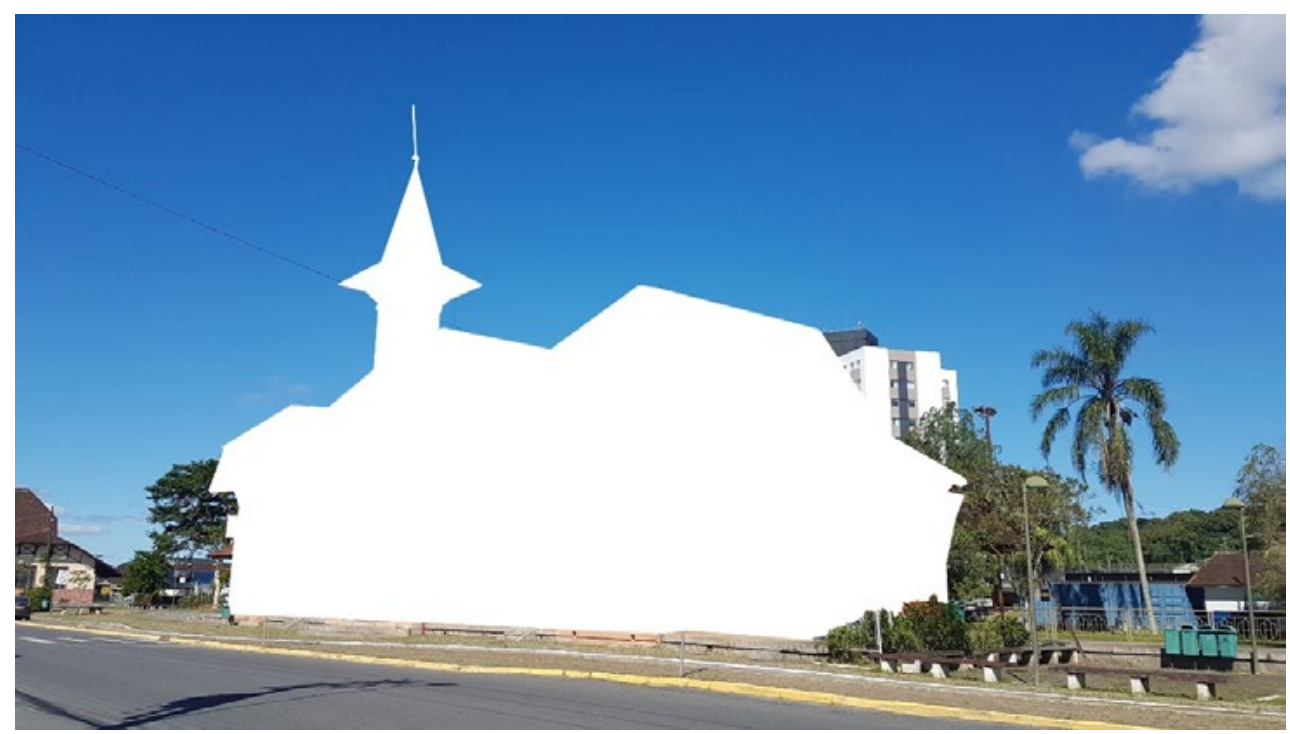

Fig. 2. Juliana Rossi Gonçalves. Estação da Memória. 2018. Foto manipulada digitalmente. Joinville/SC. 


\section{Revista Apotheke}

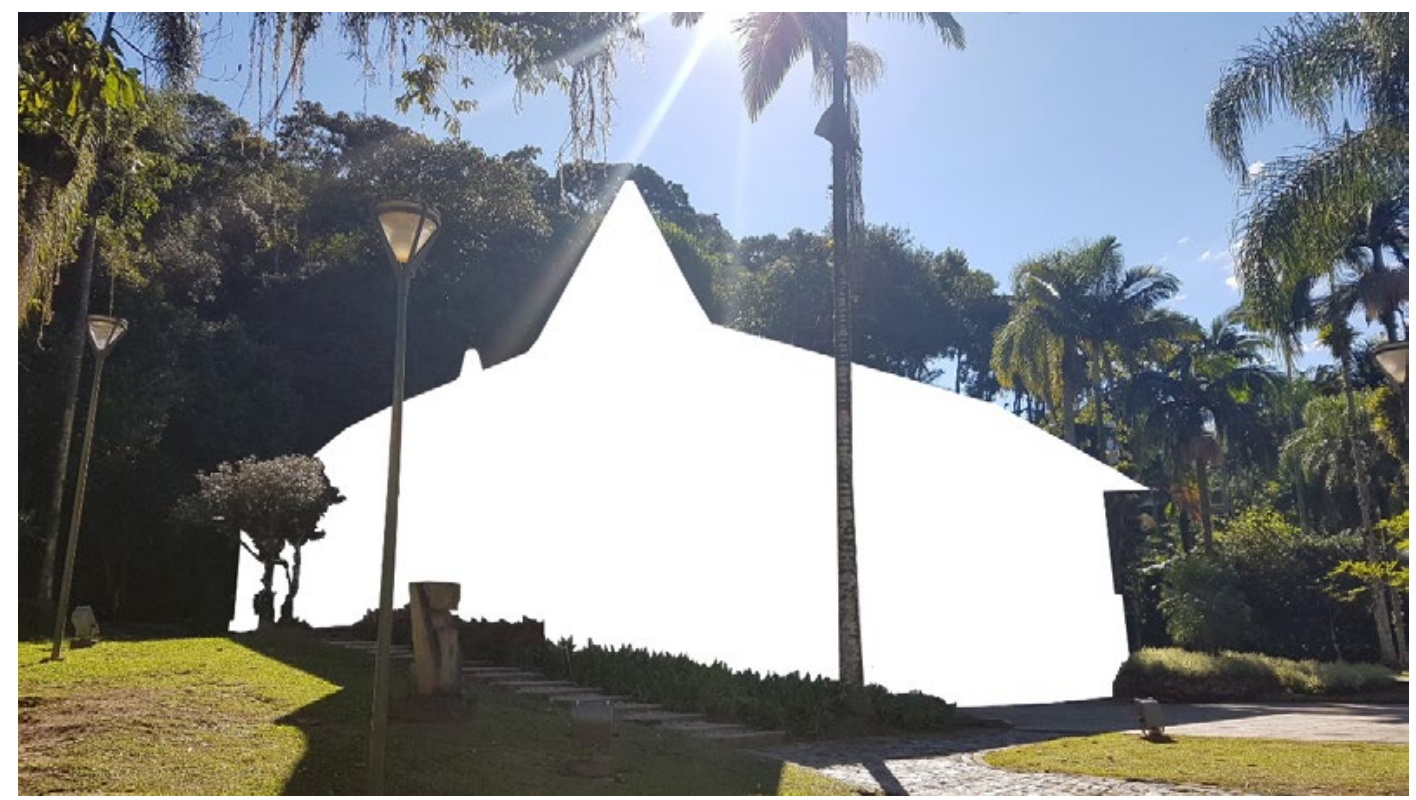

Fig. 3. Juliana Rossi Gonçalves. Museu de Arte de Joinville (MAJ). 2018. Foto manipulada digitalmente. Joinville/SC.

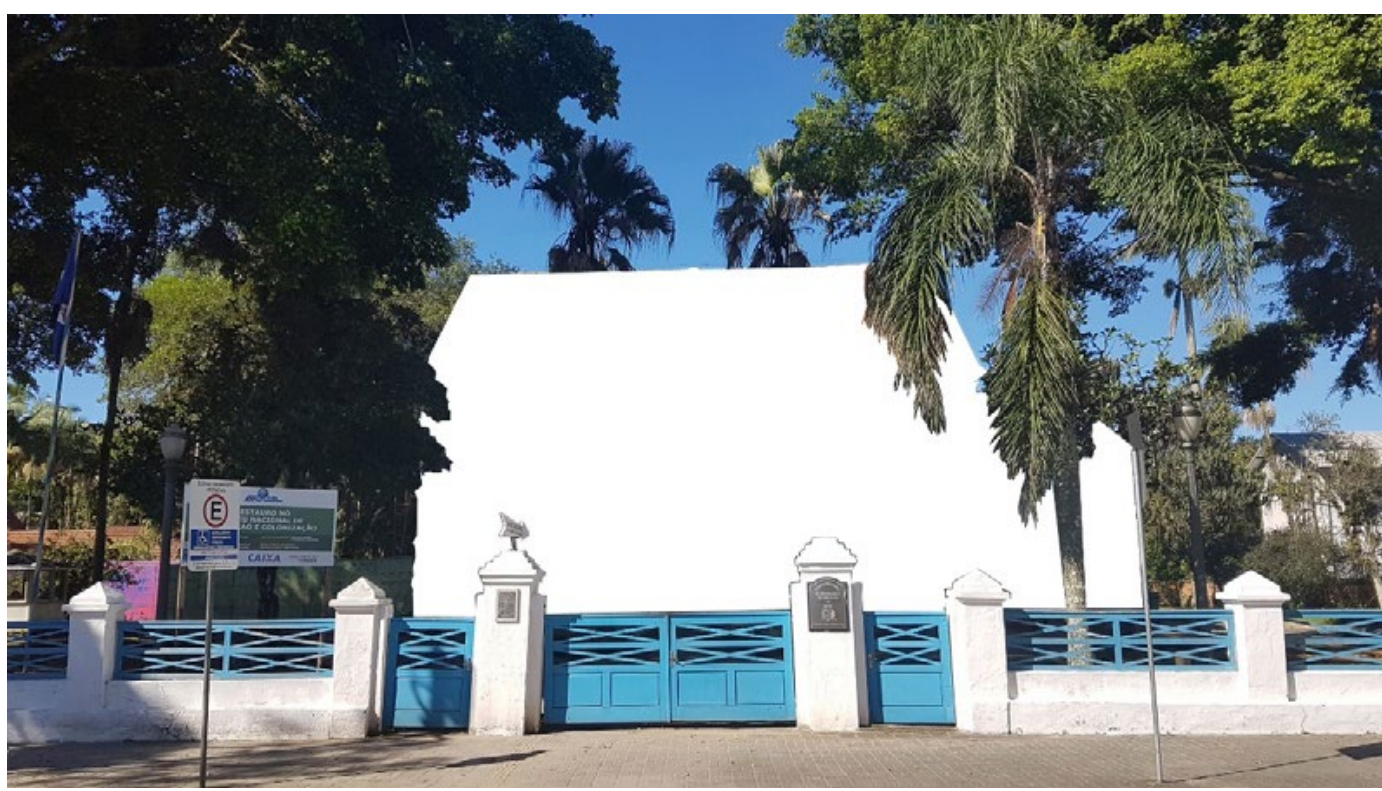

Fig. 4. Juliana Rossi Gonçalves. Museu Nacional de Imigração e Colonização de Joinville/SC. 2018. Foto manipulada digitalmente. Joinville/SC.

Assim, por meio da ausência das construções nas fotos, buscou-se discutir a efemeridade e a persistência/permanência desses espaços que já serviram em tempos passados para outros fins e atualmente são espaços culturais. A proposta direcionada para a reconstrução de olhares sobre abandono de bens patrimoniais, foi desenvolvida com três registros fotográficos manipulados que invisibilizam os bens tombados com o apagamento de suas fachadas para provocar a discussão sobre efemeridade e a persistência dos bens patrimoniais.

A expografia e a montagem da exposição foi desencadeada por alguns 
questionamentos relacionados à faixa etária do público que teria acesso à exposição e qual o padrão de altura "expositiva" mais apropriado para a colocação dos trabalhos. Esses e outros questionamentos foram solucionados coletivamente entre o grupo e a professora da disciplina.

A etapa do processo expositivo foi centralizada na discussão do papel de educador, atuante como mediador da exposição. Luciana Chen (2014) afirma que o educador deve desenvolver o seu saber ouvir, sentir e ver para buscar conexões com o educando, levando em conta o seu repertório e buscando conexões com o seu mundo. Visto que, um dos desafios constantes do educador é o de desconstruir seus pontos de vista e pré-conceitos resultantes de suas vivências para então detectar os valores dos outros, respeitando e reconhecendo as diferenças (CHEN, 2014). Portanto, a mediação cultural se constituiu no grande desafio do projeto.

\section{Desafios de uma mediação cultural em um espaço de educação formal}

Os projetos expositivos dos anos anteriores, propostos pela disciplina "Ação Educativa em Espaços Culturais" ocorreram em espaços de educação não formal, principalmente no Museu da Escola Catarinense (MESC). O Colégio de Aplicação da UFSC (CA-UFSC) foi sugerido pela Profa. Sandra objetivando expor em um espaço de educação formal, tendo como público-alvo os alunos da instituição.

O local foi selecionado por possuir um espaço expositivo denominado "Espaço Estético", idealizado pela Professora Doutora Fabíola Cirimbelli B. Costa. Exprofessora da Escolinha de Artes de Florianópolis/SC, escreveu um livro que aborda historicamente a trajetória da Escolinha². A proposição da criação de um espaço expositivo integrado ao cotidiano escolar e de livre acesso à comunidade surgiu a partir de um questionamento:

Por que não criar um espaço de exposição na escola, onde os alunos, em constante interação social, pudessem ampliar seu campo de conhecimento artístico-visual, constituindo-se leitores visuais e também autores expositores? (COSTA, 2009, p. 107).

O "Espaço Estético" promove a inserção da escola como um polo cultural, criado em 1997 em um dos corredores do Colégio de Aplicação da UFSC, abrindo possibilidades de fruição estética a partir de um calendário que abriga exposições de alunos e de artistas visuais. Esse contexto híbrido possibilita uma conexão in loco entre a produção artística contemporânea e a escola possibilitando encontros estéticos,

${ }^{2}$ COSTA, F. C. B. Escolinha de Arte de Florianópolis - 25 anos de atividade arte-educativa. 1. ed. Florianópolis/ SC: FCC, 1990. v. 1.128 p. 
Afirmando-se o caráter social de toda e qualquer criação humana, na interrelação existente entre o produto da atividade criadora e as novas e ilimitadas significações tanto para o autor/criador quando para o público/ leitor (COSTA, 2009, p. 115).

O espaço da exposição propiciou a criação de um projeto expositivo acoplado a ações de mediação cultural, visto que partimos da premissa que mediar exposições de arte é promover acesso cultural. Martins (2014, p. 259) afirma que acreditar e lutar pelo acesso cultural "abre espaços para experiências estéticas que se interligam com a percepção, pois, até independentemente do mediador, a arte e a cultura são mediadoras por si mesmas", contaminam esteticamente. A contaminação estética lida com saber interpretar signos, ler imagens, gostar de poesias.

Mediação cultural é, portanto, compreendida como ação e não função - afinal, mediamos para propor encontros significativos com a arte ou para "ensinar arte"? (MARTINS, 2014). Como propor a mediação cultural como contaminação estética? Martins (2014, p. 259) afirma que a mediação cultural não deve ser

Apenas um pensar sobre as relações entre sujeitos e a arte, mas [deve] ampliar a ação mediadora como proposições [...] que se ligam a ação do diálogo, da conversa, que pressupõem a escuta, o espaço do silêncio, a aproximação cuidadosa e sensível com o outro.

Assim, a mediação cultural proposta para o trabalho "Patrimônio em branco" foi a primeira mediação da exposição, realizada no dia da abertura em 11 de junho de 2018, construída a partir do conceito de curadoria educativa (MARTINS, 2014) com ênfase no espectador que cria a sua experiência, ou seja, como prática emancipadora que provoca e amplifica essa experiência.

A ação educativa foi dirigida para uma turma do $4^{\circ}$ ano do CA-UFSC, integrada por alunos (as) na faixa etária dos nove aos 10 anos, com visitação mediada tendo como foco a discussão dos significados de efemeridade e persistência a partir da observação do trabalho denominado "Patrimônio em Branco" (fig. 5).

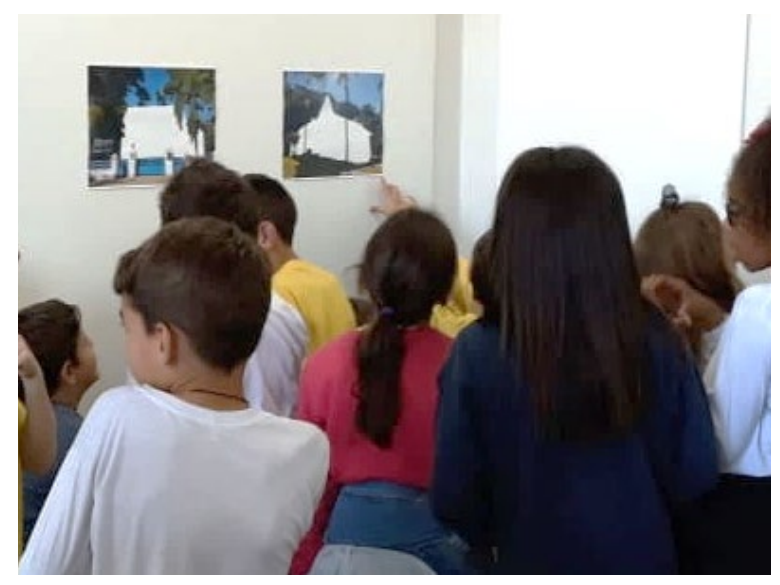

Fig. 5. Noeli Moreira. Alunos do $4^{\circ}$ ano do CA-UFSC em mediação da exposição "Efemeridades e persistências" no Espaço Estético do CA-UFSC. 2018. Florianópolis/SC. 
Os debates promovidos entre os alunos permitiram reflexões sobre o que era efêmero a partir de exemplos cotidianos como os movimentos da areia, da água dos rios, do mar e da escola; bem como sobre a dinâmica da temporalidade: o tempo passageiro das aulas, a passagem dos anos; a efemeridade do ensino contrapondo à permanência do conhecimento.

Inicialmente as crianças foram convidadas a sentar-se no chão, para observarem o trabalho "Patrimônio em Branco" e na sequência foi estabelecido um diálogo a partir de um questionamento tendo como referência as fotografias. As perguntas motivadoras/desencadeadoras do diálogo foram: "Alguém conhece Joinville? Alguém já foi a Joinville?". Essas perguntas estimularam alguns alunos integrantes do grupo a contar suas histórias pessoais sobre a cidade.

A fim de fazer uma conexão com o contexto local dos alunos, foram mostradas imagens de patrimônios de Florianópolis. Os alunos conseguiram identificar os locais patrimonializados e denotaram pertencimento e identidade com a cidade. $\mathrm{Na}$ sequência foi explanado o conceito de "tombamento", exemplificado com fotografias de bens tombados da cidade, como o Palácio Cruz e Souza, a Ponte Hercílio Luz e a Lagoa do Peri (patrimônio natural), geradores de discussões e inquietações.

A mediadora (aluna propositora) perguntou sobre o que significava para eles a destruição das construções, ou da natureza, como os parques naturais. A partir das respostas das crianças, foi possível estabelecer conexões e acionar alguns conceitos sobre patrimônio e proteção por meio da reflexão sobre construções arquitetônicas ou espaços naturais a ser preservados como bens patrimoniais materiais, praias e parques naturais.

Nesse primeiro momento, as crianças refletiram sobre a importância de valorizar e proteger esses espaços construídos e naturais pois, defender o patrimônio cultural é reconhecer a história e trajetória do passado e dos sujeitos que já passaram por ali e que constituem a identidade local.

Após a mediação realizada no "Espaço Estético", os alunos foram encaminhados à sala de aula para produzirem um trabalho artístico referente à ação educativa ocorrida na exposição, tematizando "Patrimônio em branco". O início da atividade foi desencadeado por uma colagem de pequenos textos no quadro de giz sobre cada patrimônio retratado no trabalho exposto com informações a respeito do ano de construção e a função dos espaços antes de serem tombados como patrimônios culturais e transformados em espaços culturais:

- "Museu de Imigração e Colonização: construção finalizada em 1870, tombada em 1939. O dono da casa era administrador do príncipe de Joinville (cidade na França), que recebeu as terras de Joinville como parte de dote de casamento com a Princesa Francisca, filha do Rei Dom Pedro I" (MUSEU NACIONAL DE IMIGRAÇÃO E COLONIZAÇÃO, 2019);

- "Museu de Arte de Joinville: finalizado em 1864, tombado em 2002. Uma das casas mais antigas de Joinville. Foi casa de Ottokar Döerffel, político que criou o primeiro jornal da cidade" (MUSEU DE ARTE DE JOINVILLE, 2018); 
- "Estação da Memória: antiga Estação Ferroviária. Fazia o trajeto JoinvilleSão Francisco do Sul/SC e foi inaugurada em 1906. Tombada em 1996. Comprada pela Prefeitura em 1999, esteve fechada e tornou-se ponto turístico a partir de 2003, depois de uma restauração e reforma" (ESTAÇÃO DA MEMÓRIA, 2018).

Após um diálogo inicial, na sequência foi proposta uma atividade prática, desenhar dentro dos espaços em branco em fotocópias das fotos expostas na Mostra, construções imaginadas, recriando o patrimônio apagado a partir de informações sobre detalhes arquitetônicos dos espaços apagados. Por exemplo, informamos que no "Museu de Imigração" na parede frontal há uma sacada e várias colunas. No período de tempo proposto para a mediação, os alunos conseguiram trabalhar somente com a foto do Museu de Imigração (fig. 6).
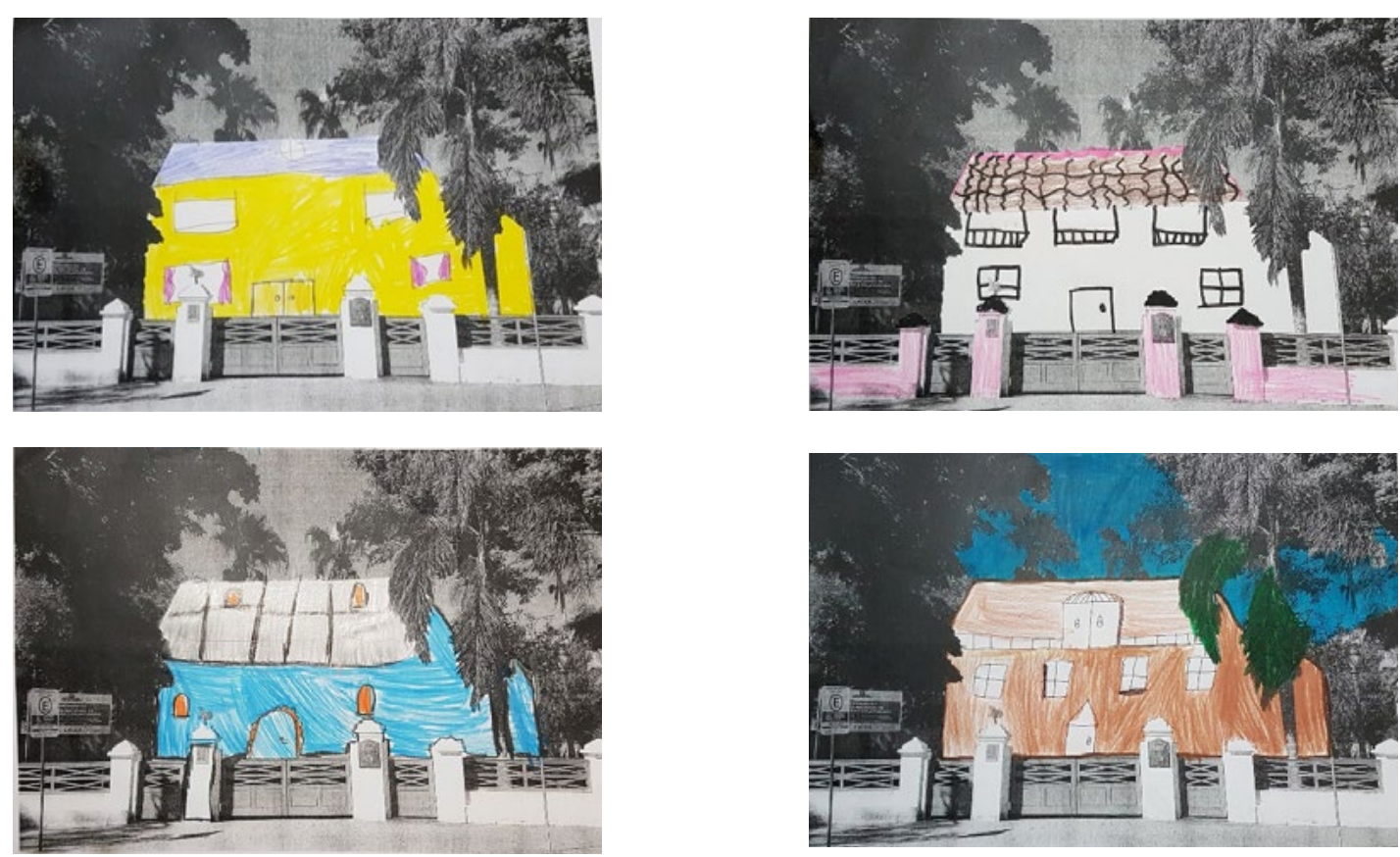

Fig. 6. Juliana Rossi Gonçalves. Montagem com quatro fotografias de trabalhos produzidos por alunos do $4^{\circ}$ ano do Colégio de Aplicação da UFSC - intervenção sobre fotocópia em preto e branco de fotografia manipulada digitalmente. 2018. Florianópolis/SC.

Os desenhos dos alunos produzidos a partir das fotocópias dos trabalhos demonstraram de que forma puderam contextualizar sua imaginação às informações patrimoniais, disponibilizadas no quadro branco, agregada às informações das construções. Aspectos perceptíveis em alguns desenhos em que há grandes janelas nas casas - informação passada pela mediadora.

Em grande parte, os desenhos apresentam telhados na construção, constatando e simulando detalhes do bem patrimonial onde há linhas diagonais no local vazado da foto. Ou seja, o formato do recorte digital realizado na imagem pela aluna propositora deixou resquícios de suas construções, fazendo com que os alunos pudessem acessar seus repertórios imagéticos, a partir de imagens pré-definidas que já tiveram acesso. 
No dia seguinte após a atividade, a Profa. Fabiola mostrou aos alunos algumas fotos dos espaços originais que foram "apagados" no trabalho "Patrimônio em Branco" (fig.7). Segundo Fabiola (COSTA, 2020), ao apresentar as imagens, os estudantes indagaram sobre o local onde os bens patrimoniais estavam localizados. Alguns externaram que imaginaram espaços diferentes, outros fizeram associações visando localizar esses espaços em Florianópolis e estabeleceram ligações com suas criações artísticas realizadas no momento da ação educativa (COSTA, 2020).
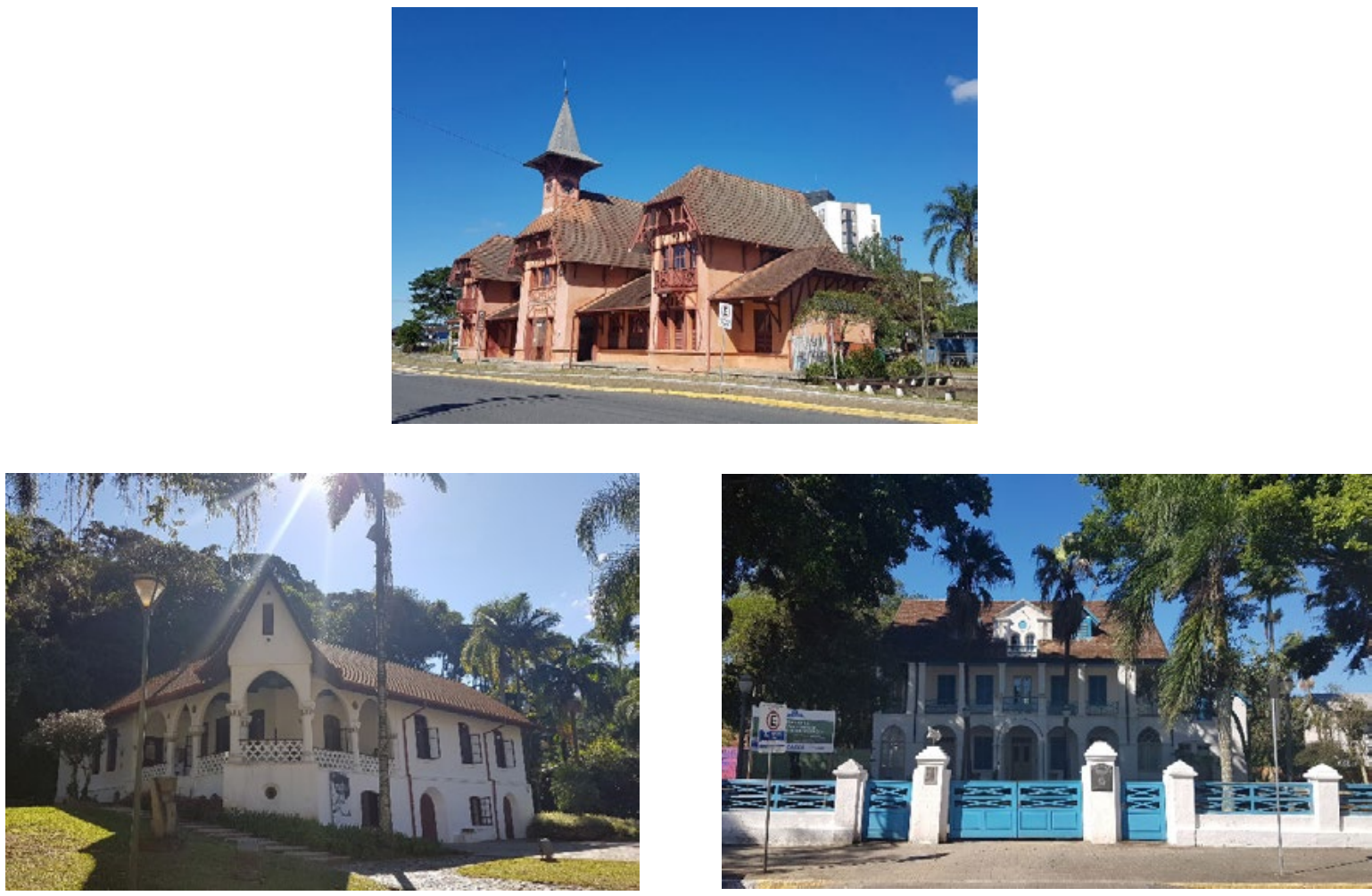

Fig. 7. Juliana Rossi Gonçalves. Montagem das fotos originais das instituições culturais fotografadas para o trabalho "Patrimônio em branco", da esq. para a dir.: Estação da Memória, Museu de Arte de Joinville, Museu Nacional de Imigração e Colonização. 2018. Joinville/SC.

O momento da atividade prática gerou um grande envolvimento com a turma, devido a possibilidade de "tocar" e de interferir diretamente nas fotos. Essa interação direta aconteceu em trabalhos de outras alunas propositoras no momento da mediação, experiência que tornou as crianças participantes ativos da exposição pelo uso de pincéis, lápis e canetinhas.

Em relação ao tríptico "Patrimônio em branco" foi necessário levar os alunos para a sala de aula, a fim de permitir o momento da prática artística, pois o trabalho em si na mostra não permitia esse tipo de interferência. Durante a atividade em sala de aula foi viabilizado um espaço para diálogo preparatório. Porém, o tempo só permitiu a intervenção em uma imagem. Por esse motivo, muitos alunos (as) pediram para levar as outras imagens consigo, pois iriam finalizar em casa.

A limitação do tempo é algo comum nos cotidianos das aulas de artes nas escolas formais, cronometrado por um padrão que inviabiliza a liberdade criativa alheia às 
marcações do relógio.

O processo de mediação proposto reafirmou as observações de Chen (2014, p. 6) sobre a conexão entre o espaço formal e não formal:

Constata-se a importância de ambos os espaços educativos para o aprendizado da arte, cada qual fornecendo o que lhe é característico: o contato com obras originais no espaço não-formal, exibindo o que é apresentado virtualmente em aula teórica com seus contextos e servindo de exemplo para o desenvolvimento de técnicas e modos de expressão para aulas práticas no ensino formal. Destaca-se que o trabalho realizado em cada lugar pode ser conectado ao outro.

O ato criador não é executado pelo artista sozinho - o público estabelece o contato entre a obra de arte e o mundo exterior, acrescentando sua contribuição ao ato criador, decifrando e interpretando suas qualidades intrínsecas (DUCHAMP, 1975 apud MARTINS, 2014). A obra contemporânea representa um potencial de comunicação entre o artista e o público, e é o público que estabelece o contato entre a obra e o mundo exterior.

Nessa proposição, o "Espaço Estético" do CA-UFSC como um espaço escolar abriu espaço para um projeto expositivo de arte visual vislumbrando experiências estéticas na escola.

\section{Considerações finais}

A produção e mediação da exposição "Efemeridades e Persistências" realizada pelas mestrandas e doutorandas em 2018 na disciplina "Ação Educativa em Espaços Culturais" suscitou diversas experiências no campo da produção artística e mediação cultural. Bem como, possibilitou às discentes conhecer diversos espaços culturais de Florianópolis/SC, além da análise de materiais educativos com base em textos lidos.

A mediação cultural relatada nesse artigo foi um processo desafiador e desencadeou reflexões sobre os conceitos de efemeridade e persistência, interligando questões associadas à valorização e à salvaguarda do patrimônio cultural. Propiciou também a identificação de espaços locais preservados como patrimônios culturais por parte dos alunos - estratégia pedagógica que teve como ponto de partida o repertório dos alunos e contribuiu para que as informações transmitidas fossem acionadas e retrabalhadas nos trabalhos artísticos realizados pelo grupo envolvido.

Outro aspecto constatado a partir da experiência de mediação cultural foram os desafios diários a serem enfrentados pelos professores de artes, que além da constante desvalorização da disciplina como complementar e da falta de material, sofrem preconceitos e retaliações de cunho político e ideológico. Os professores de ensino de arte atuam como propositores de ações educativas a partir de conhecimentos teóricos e práticos.

$\mathrm{Na}$ escola cabe ao professor promover o acesso cultural aos seus alunos ao 
construir curadorias educativas que ampliem o repertório, oferecendo acesso não só à arte, mas também ao patrimônio cultural. $O$ conhecimento da arte não termina na obra de arte, é uma construção coletiva de conhecimento e uma ferramenta para compreender o mundo (HELGUERA, 2011).

Sobre as efemeridades e persistências, Ramalho e Oliveira (2018) afiança que

Ainda podemos pensar também na efemeridade do ensino, nas mutações das teorias e metodologias, de ensino e de pesquisa, nas transformações do conhecimento, nas verdades provisórias, nas mudanças sociais e culturais; e, em termos de arte, não apenas trabalhos de arte podem ser efêmeros, mas as próprias exposições de arte, pois excetuando-se as que são itinerantes, as demais são únicas, não voltam jamais e proporcionam experiências exclusivas daquela curadoria/montagem.

Essa experiência ocorrida em 2018 foi efêmera, mas os ensinamentos para as alunas propositoras permanecem, bem como também suscitam novos desafios e demandas que vêm com as permanências e efemeridades da vida.

\section{Referências}

CHEN, Luciana. Reflexões sobre a educação formal e não-formal a partir da semiótica discursiva. In: XX Colóquio do Centro de Pesquisas Sociossemióticas, 2014, São Paulo. Anais XX Colóquio do Centro de Pesquisas Sociossemióticas (PUC - SP), São Paulo. Editora da PUC - SP, 2014.

COSTA, Fabiola Cirimbelli Búrigo. Espaço estético no contexto escolar. Revista Sobre Tudo: Florianópolis, v. 6, p. 105-119, 2009.

COSTA, Fabiola Cirimbelli Búrigo. Mostra efemeridades (2018) [mensagem pessoal]. Mensagem recebida por <julirossi@gmail.com> em 16 jun. 2020.

COUTINHO, Rejane Galvão. O educador pesquisador e mediador: questões e vieses. Pós: Belo Horizonte, v. 3, n. 5, p. 46 - 55, maio, 2013.

ESTAÇÃO DA MEMÓRIA. Disponível em: <https://pt.wikipedia.org/wiki/ Esta\%C3\%A7\%C3\%A3o_da_Mem\%C3\%B3ria>. Acesso em 7 jan. 2020.

GONÇALVES, Juliana Rossi. Patrimônio em branco. In: Efemeridades e Persistências. Etiqueta do trabalho exposto. Florianópolis: UDESC e Colégio da Aplicação da Universidade Federal de Santa Catarina. 2018.

GROSSMANN, Martin. Museu como interface. In: GROSSMANN, Martin; MARIOTTI, Gilberto (Org.). Museum Art Today/Museu Arte Hoje. São Paulo: Hedra e Fórum Permanente, 2011. P. 193-221. 
HELGUERA, Pablo. Transpedagogia. In: HELGUERA, Pablo; HOFF, Mônica. (Orgs.). Pedagogia no campo expandido. Porto Alegre: Fundação Bienal do Mercosul, 2011. P. 11-31.

MARTINS, Miriam Celeste. Mediações culturais e contaminações estéticas. Revista GEARTE: Porto Alegre, v. 1, n. 2, p. 248-264, ago. 2014. Disponível em: <http://seer.ufrgs.br/index. php/gearte/article/view/52575>. Acesso em: 12 jan. 2020.

MUSEU DE ARTE DE JOINVILLE. Disponível em: <https://pt.wikipedia.org/wiki/Museu_de_ Arte_de_Joinville>. Acesso em 7 jan. 2020.

MUSEU NACIONALDE IMIGRAÇÃO E COLONIZAÇÃO. Disponível em: <https://pt.wikipedia. org/wiki/Museu_Nacional_de_Imigra\%C3\%A7\%C3\%A3o_e_Coloniza\%C3\%A7\%C3\%A3o>/. Acesso em 7 de jan. 2020.

RAMALHO E OLIVEIRA, Sandra Regina. Efemeridades e Persistências. In: Efemeridades e Persistências. Convite da Mostra. Florianópolis: UDESC e Colégio da Aplicação da Universidade Federal de Santa Catarina. 2018.

Recebido em 12 de maio de 2020.

Aprovado em 24 de junho de 2020. 